\title{
CHK2 Immunohistochemical Expression in Colon Cancer and its Relation with Clinicopathological Features and Outcome in Metastatic Colon Cancer Patients
}

Karen Bento Ribeiro', Juliana da Silva Zanetti², Alfredo Ribeiro Silva ${ }^{3}$, Fabiana Pansani², Sergio Britto Garcia ${ }^{3}$, Omar Feres ${ }^{4}$, José Joaquim Ribeiro da Rocha ${ }^{4}$ and Fernanda Maris Peria ${ }^{1}$

${ }^{1}$ Clinical Oncology, FMRP-USP (SP), Clinical Oncology Service, FMRP-USP (SP), Brazil

${ }^{2}$ Biomedical, FMRP-USP, Brazil

${ }^{3}$ Pathology, FMRP-USP (SP), Brazil

${ }^{4}$ Department of Surgery and Anatomy, FMRP-USP (SP), Brazil

\begin{abstract}
Background: The DNA damage checkpoint pathway has been of interest to the field of cancer biology, since checkpoint defects result in the accumulation of altered genetic information, a central feature of carcinogenesis. Little is known about the role that CHK2 (checkpoint kinase 2) gene plays in colorectal cancer tumorigenesis. The purpose of this study was to evaluate CHK2 expression in metastatic colon cancer and correlate it with clinicopathological features and patient survival.
\end{abstract}

Methods: Tissues of primary tumors were obtained from 58 patients with metastatic colon cancer. The tissue microarray immunohistochemistry was the technique used to evaluate $\mathrm{CHK2}$ expression. Statistical analysis used was SPSS17; $p$-value was set at $<0.050$. The relationship between the CHK2 immunohistochemical expression and the patients' clinical and pathological features as well as survival data was reported.

Results: CHK2 expression was positive in $69 \%$ of the cases. CHK2 expression was associated with lymph node status $(p=0.012)$ and survival $(p=0.034)$. Negative CHK2 expression increased the chance of lymph node involvement (Odds ratio: 10.23, $p=0.03$ ). The global survival time of $C H K 2$-negative patients was higher (72 versus 59 months); the same trend emerged for progression-free survival time (19 versus 13 months). The survival curves differed depending on CHK2 expression in patients with or without lymph node involvement; survival was lower in CHK2-positive. A larger number of deaths occurred in CHK2-positive. Multivariate regression analysis identified performance status ECOG $(p=0.01)$, synchronous metastasis $(p=0.037)$, tumor cell differentiation $(p=0.029)$ and CHK2 expression $(p=0.020)$ as independent factors for overall survival.

Conclusions: This study demonstrated that positive CHK2 expression in colon cancer indicates aggressiveness and impacts negatively patient survival and outcome. On the other hand, a negative expression indicates dissemination to lymph nodes.

Keywords: Checkpoint kinase 2; Colorectal cancer; Immunohistochemistry

\section{Introduction}

Accumulation of mutations and chromosomal abnormalities, alterations in tumor suppressor genes and activation of proto-oncogenes constitute marked features of carcinogenesis. The genetic instability of malignant cells can perpetuate along generations, which is a result of impaired repair mechanisms and defective maintenance of human genome integrity (DNA repair via checkpoints of the cell cycle). As a consequence, malignant cells acquire the ability to undergo unlimited multiplication and to invade local and distant tissues $[1,2]$.

Checkpoints cellular signaling pathways are activated in response to any cellular DNA damage or genetic errors. They trigger repair processes or lead to cell apoptosis via intra- and intercellular downstream signaling of effector protein kinases [2,3]. Among such kinases, the family of enzymes Chk1 (checkpoint kinase 1) and Chk2 (checkpoint kinase 2), which can arrest the cell cycle and induce apoptosis in response to cellular DNA damage, acts as tumor suppressors; especially CHK2 [4].

Chk2 is stable protein expressed along the cell cycle. It remains inactive in absence of cellular DNA damage. However, if external stimulation with ionizing ultraviolet radiation or cytotoxic drugs elicits DNA damage via ATM (Ataxia telangiectasia mutated), Chk2 phosphorylates various substrates, including p53, BRCA1, Mdm2, Cdc25A and Cdc25C. Signaling is then propagated at the nuclear level, to activate mechanisms of cell repair and apoptosis $[2,5]$.

The development of cancer related to defects arising from $\mathrm{CHK1}$ gene is extremely rare. Nevertheless, somatic mutations of CHK2 gene occur in some sporadic human tumors (breast, lung, vulva, bladder, colon, ovary carcinomas, osteosarcoma and lymphoma). These mutations can produce unstable proteins that are easy to degrade; diminish protein kinase activity or impair recognition of their substrates. In these tumors, immunohistochemical staining of $\mathrm{CHK} 2$ is significantly reduced or lost $[2,6]$.

*Corresponding author: Fernanda Maris Peria, Departamento de Clínica, Médica da FMRP-USP, Divisão de Oncologia Clinica Av. Bandeirantes, 3900, Ribeirão Preto-SP, Brazil, Tel/Fax: 5516 3602-2304; E-mail: fernandaperia@fmrp.usp.br

Received September 20, 2014; Accepted October 18, 2014; Published October 20, 2014

Citation: Ribeiro KB, da Silva Zanetti J, Ribeiro Silva A, Pansani F, Garcia SB, et al. (2014) CHK2 Immunohistochemical Expression in Colon Cancer and its Relation with Clinicopathological Features and Outcome in Metastatic Colon Cancer Patients. J Cytol Histol 5: 288. doi:10.4172/2157-7099.1000288

Copyright: (c) 2014 Ribeiro KB, et al. This is an open-access article distributed under the terms of the Creative Commons Attribution License, which permits unrestricted use, distribution, and reproduction in any medium, provided the original author and source are credited. 
Citation: Ribeiro KB, da Silva Zanetti J, Ribeiro Silva A, Pansani F, Garcia SB, et al. (2014) CHK2 Immunohistochemical Expression in Colon Cancer and its Relation with Clinicopathological Features and Outcome in Metastatic Colon Cancer Patients. J Cytol Histol 5: 288. doi:10.4172/21577099.1000288

The protein Chk2 is more activated in precursor neoplastic lesions of colon, bladder, breast and lung, which suggests that the checkpoints pathway is more activated in early stages of tumorigenesis. Mutations in $C H K 2$ or in other genes involved in ATM-CHK2-p53 pathway allow the cells to survive the repair mechanisms, which culminates in proliferation and survival of abnormal cells and results in increased genetic instability and tumor progression [5]. There are lower levels of pChk2 (phosphorylated protein form of checkpoint kinase 2) in initial stages of cancer and higher pChk2 expression in tumors with lymph node involvement [3].

Reduced CHK2 and pChk2 expression contributes to the development of colon-rectal cancer. However, increased expression of these proteins seems to be associated with degree of tumor malignancy [3]. Information about immunohistochemical expression of CHK2 in human tumor tissues is limited. Therefore, the present study aims to characterize the protein expression of CHK2 in metastatic colon cancer and correlate it with clinicopathological features and patient survival by immunohistochemistry.

\section{Materials and Methods}

\section{Materials}

This study included paraffin-embedded tumor tissue samples of 58 patients diagnosed with colon cancer sporadic, submitted to resection of the primary tumor, and treated at Clinical Oncology Service of HCFMRP-USP (Hospital das Clínicas da Faculdade de Medicina de Ribeirão Preto- Universidade de São Paulo) between 2003 and 2013. None of the patients had received any previous local or systemic treatment. The inclusion criteria were patients with metastatic colon cancer disease to lung and/or liver and CHK2 analysis from primary tumor tissue.

\section{Methods}

Clinical information was retrospectively collected from medical records and included histopathological features, overall survival (OS), progression-free survival (PFS) and metastasis (lung and liver). OS was defined as the time elapsed since diagnosis until death and PFS was the time elapsed since diagnosis until disease progression (local or distant) or death. Synchronous metastasis referred to distant metastasis at the time of primary cancer diagnosis or up to six months after it; metachronous metastasis was any metastatic lesion detected after this period [7]

\section{Preparation of Tissue Microarrays (TMA)}

A metallic marker (Hystopathology Ltd., Hungary) was used to remove a cylindrical fragment of representative and central area of the tumor. The removed fragments were placed in receptor block ( 24 positions).

Histological cuts with a thickness of $3 \mu \mathrm{m}$ were made on each of the prepared TMA blocks; conventional rotary microtome (Microm HM315, Walldorf, Alemanha) and paraffin tape-transfer system (Instrumedics, Saint Louis, USA) were used for this. A cut was reserved for staining with HE to confirm the presence of tumor in the TMA cylinder. Histological cuts were mounted for accomplishment of immunohistochemical assays [8]. For cylinders with less than $50 \%$ of the total cylinder a new TMA cut was carried out.

\section{Immunohistochemical method}

Endogenousperoxidaseblockingwasused forimmunohistochemical reaction protocol, conducted with the aid of the REVEAL polymer kit
(Spring, BIOGEN- Hamburg, Germany). The checkpoint kinase 2 antibody, clone DCS270.1 (Novocastra, Newcastle upon Tyne, UK), was employed at 1:50 dilution.

The slides were deparaffinized in xylol and hydrated in ethanol and water. Endogenous peroxidase activity was blocked in $0.3 \%$ hydrogen peroxide solution in a steamer containing sodium citrate buffer $0.001 \mathrm{M} \mathrm{pH} 6.0$. They were incubated with primary antibody, followed by incubation with biotinylated secondary antibody (kit REVEAL BIOGEN), application of HRP polymer conjugate (Horseradish peroxidase) and washing with TBS buffer (Tris buffer saline). The reaction was revealed by staining with diaminobenzidine peroxidase (DAB). The slides were counterstained with hematoxylin and analyzed under conventional light microscope at 40x magnification (Axiostar Plus, Zeiss, Göttingen, Germany).

The negative control was prepared by suppression of primary antibody. The positive control consisted of immunohistochemical reaction on healthy mammary gland tissue. All neoplastic cells containing dark brown stained nucleus were considered positive. The case was considered CHK2-positive if the TMA cylinder presented at least $60 \%$ of neoplastic cells with moderate to intense immunoreactive nucleus [1,9] (Figure 1).

\section{Statistical Analysis}

Statistical analysis was conducted using the software SPSS17. Association between the variables was analyzed by Chi-square and Fisher exact test. Analysis of the association between CHK2 immunohistochemical expression (negative or positive) and gender (male; female), age ( $>65$ years; $<65$ years), histology (adenocarcinoma; mucinous carcinoma), $\mathrm{T}$ stage (T2; T3; T4), $\mathrm{N}$ stage (N0; N1; N2), clinical stage (CS II; CS III; CS IV), perforated/obstructed acute abdomen (present; absent), metastasis (synchronous; metachronous), lymph node involvement (present; absent), survival (alive; dead), recurrence (present; absent), lung metastasis (present; absent), liver metastasis (present; absent), degree of cell differentiation (grade I and II; grade III), and ECOG $(0$ and $1 ; 2)$ were conducted.

Survival analysis were assessed using Kaplan-Meier and long-rank test was used to compare the survival groups (CHK2-positive versus CHK2-negative). The patients were included at different times during the follow up.

To verify the interaction between CHK2 immunohistochemical expression and the variables, the logistic regression was used to obtain Odds Ratio (OR) and how the CHK2 immunohistochemical expression interacted with OS, PFS, lymph node involvement and liver and lung
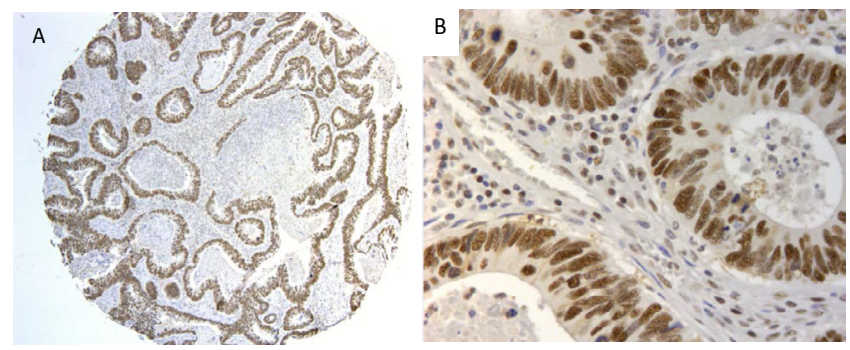

Figure 1: (A) TMA cylinder containing a section of the material bearing colon adenocarcinoma, considered as positive (over $60 \%$ positive nuclear immunostaining, 5x magnification). (B) Neoplastic colon cells showing immunoreactivity for CHK2 (nuclear staining, immunohistochemistry, 400x). 
Citation: Ribeiro KB, da Silva Zanetti J, Ribeiro Silva A, Pansani F, Garcia SB, et al. (2014) CHK2 Immunohistochemical Expression in Colon Cancer and its Relation with Clinicopathological Features and Outcome in Metastatic Colon Cancer Patients. J Cytol Histol 5: 288. doi:10.4172/21577099.1000288

Page 3 of 5

metastases the cox model for proportional risks was employed to achieve the Hazard Ratio (HR). The p-value was set at 0.05 .

\section{Results}

In this cohort, $40(69 \%)$ and $18(31 \%)$ patients presented positive and negative CHK2 immunohistochemical expression, respectively. The patients were aged between 24 and 89 years, with mean and median of 57.3 and 54 years, respectively. The clinical and histopathological characteristics are described in Table 1.

At the end, 47 (81\%) and 27 (46.5\%) patients presented with liver and lung metastases, respectively. Only nine (15.5\%) patients did not face tumor recurrence or progression and $37(63.8 \%)$ patients remained alive until the end of data analysis. The mean and median OS was 63 and 47 (34-60) months, respectively and for PFS was 14.5 and 11 (813) months, respectively.

The association of CHK2 expression with lymph node involvement status and OS was significant. At the end, CHK2- negative was more frequent in live patients (Table 2). Patients with CHK2-negative primary tumors had tenfold higher chance of lymph node involvement as compared with CHK2-positive (OR:10.2; IC95\%: 22-84.6, $p=0,031$ ).

The CHK2-negative OS patients was 72.2 months (95\%CI: 48-96 months) on average; this was not different $(p=0.115)$ from CHK2positive (59.5 months, 95\%CI: $41-78$ months). To PFS, the CHK2negative and CHK2-positive patients did not differ either (19.3; 95\%CI: 8.8-29.8 months, and 13.3 months; $95 \%$ CI: 9.7-17 months, respectively, $p=0.293$ ).

After adjustment for lymph node involvement, the CHK2-negative OS and CHK2-positive OS patients were different $(p=0.028)$. The same occurred after adjustment for liver metastasis-a higher number of deaths also took place among $C H K 2$-positive patients as compared with CHK2-negative $(p=0.05)$.

The survival among patients with synchronous and metachronous metastasis was 28.2 (95\%CI: 23.4-33 months) and 81.5 months (95\%CI: 6.1-102.8 months), respectively $(p=0.05)$. In synchronous metastasis group, CHK2-negative patients presented longer OS as compared with CHK2-positive: 35.4 (95\%C: $25.9-44.9$ months) and 15.1 months (95\%CI: 20.6-19.6 months), respectively $(p=0,05)$. In metachronous metastasis group, CHK2-negative patients also exhibited longer OS as

\begin{tabular}{|l|c|c|c|}
\hline Clinical characteristics & Total: $\mathbf{5 8}$ & $\begin{array}{c}\text { Histopathological } \\
\text { characteristics }\end{array}$ & Total: $\mathbf{5 8}$ \\
\hline Male/female & $32 / 26$ & $\begin{array}{c}\text { Adenocarcinoma/mucinous } \\
\text { carcinoma }\end{array}$ & $50 / 8$ \\
\hline Elderly/non-elderly & $19 / 39$ & $\begin{array}{c}\text { Well to moderately differentiated } \\
\text { /little differentiated }\end{array}$ & $53 / 5$ \\
\hline ECOG 0-1/2 & $54 / 4$ & T2/T3/T4 & $5 / 38 / 15$ \\
\hline $\begin{array}{l}\text { OPAA } \\
\text { present/absent }\end{array}$ & $16 / 42$ & N+/N0 & $42 / 16$ \\
\hline $\begin{array}{l}\text { Synchronous and } \\
\text { metachronous } \\
\text { metastasis }\end{array}$ & $36 / 22$ & CSII/CSIII/CSIV & $8 / 14 / 36$ \\
\hline
\end{tabular}

Table 1: Distribution of the clinical and histopathological characteristics of the overall sample of patients with colon carcinoma. Caption: ECOG = Eastern Cooperative Oncology Group. ECOG 0: fully active, able to carry on all pre-disease performance without restriction. ECOG 1: restricted in physically strenuous activity but ambulatory and able to carry out work of a light or sedentary nature. ECOG 2: ambulatory and capable of all self-care activities but unable to carry out any work activities, up and about more than $50 \%$ of waking hours. OPAA: obstructed/ perforated acute abdomen; $\mathrm{T}$ : degree of tumor involvement; $\mathrm{N}$ : degree of lymph node involvement, where $\mathrm{N}+$ : presence of lymph node involvement and $\mathrm{NO}$ : absence of lymph node involvement; CS: clinical stage.

\begin{tabular}{|c|c|c|c|}
\hline Feature & $\begin{array}{l}\text { ChK2-negative } \\
\text { (18) }\end{array}$ & $\begin{array}{c}\text { ChK2-positive } \\
\text { (40) }\end{array}$ & p-value \\
\hline $\begin{array}{l}\text { Gender } \\
\text { Male } \\
\text { Female }\end{array}$ & $\begin{array}{c}12 \\
6\end{array}$ & $\begin{array}{l}20 \\
20\end{array}$ & 0.268 \\
\hline $\begin{array}{l}\text { Age } \\
>65 \text { years } \\
<65 \text { years }\end{array}$ & $\begin{array}{c}4 \\
14\end{array}$ & $\begin{array}{l}15 \\
25\end{array}$ & 0.367 \\
\hline $\begin{array}{l}\text { Histology } \\
\text { Adenocarcinoma } \\
\text { Mucinous carcinoma }\end{array}$ & $\begin{array}{c}17 \\
1\end{array}$ & $\begin{array}{c}33 \\
7\end{array}$ & 0.413 \\
\hline $\begin{array}{l}\text { Stage T } \\
\text { T2 } \\
\text { T3 } \\
\text { T4 }\end{array}$ & $\begin{array}{c}3 \\
10 \\
5\end{array}$ & $\begin{array}{c}2 \\
28 \\
10\end{array}$ & 0.302 \\
\hline $\begin{array}{l}\text { Stage N } \\
\text { N0 } \\
\text { N1 } \\
\text { N2 }\end{array}$ & $\begin{array}{l}1 \\
8 \\
9\end{array}$ & $\begin{array}{l}15 \\
11 \\
14\end{array}$ & 0.042 \\
\hline $\begin{array}{l}\text { Clinical Stage }(E C) \\
\text { CSII } \\
\text { CSIII } \\
\text { CSIV }\end{array}$ & $\begin{array}{c}0 \\
7 \\
11\end{array}$ & $\begin{array}{l}8 \\
7 \\
25\end{array}$ & 0.051 \\
\hline $\begin{array}{l}\text { Obstructed/perforated acute } \\
\text { abdomen (OPAA) } \\
\text { Present } \\
\text { Absent }\end{array}$ & $\begin{array}{c}6 \\
12\end{array}$ & $\begin{array}{l}10 \\
30\end{array}$ & 0.538 \\
\hline $\begin{array}{l}\text { Metastasis } \\
\text { Synchronous } \\
\text { Metachronous }\end{array}$ & $\begin{array}{c}11 \\
7\end{array}$ & $\begin{array}{l}25 \\
15\end{array}$ & 1.0 \\
\hline $\begin{array}{l}\text { Lymph node involvement } \\
\text { Present } \\
\text { Absent }\end{array}$ & $\begin{array}{c}17 \\
1\end{array}$ & $\begin{array}{l}25 \\
15\end{array}$ & 0.012 \\
\hline $\begin{array}{l}\text { Death } \\
\text { Yes } \\
\text { No }\end{array}$ & $\begin{array}{c}3 \\
15\end{array}$ & $\begin{array}{l}18 \\
22\end{array}$ & 0.044 \\
\hline $\begin{array}{l}\text { Recurrence } \\
\text { Yes } \\
\text { No }\end{array}$ & $\begin{array}{c}13 \\
5\end{array}$ & $\begin{array}{c}36 \\
4\end{array}$ & 0.119 \\
\hline $\begin{array}{l}\text { Liver metastasis } \\
\text { Present } \\
\text { Absent }\end{array}$ & $\begin{array}{c}16 \\
2\end{array}$ & $\begin{array}{c}31 \\
9\end{array}$ & 0.474 \\
\hline $\begin{array}{l}\text { Lung metastasis } \\
\text { Present } \\
\text { Absent }\end{array}$ & $\begin{array}{c}10 \\
8\end{array}$ & $\begin{array}{l}17 \\
23\end{array}$ & 0.404 \\
\hline $\begin{array}{l}\text { Degree of tumor cell differentiation } \\
\text { Grade I+II } \\
\text { Grade III }\end{array}$ & $\begin{array}{l}16 \\
2\end{array}$ & $\begin{array}{c}37 \\
3\end{array}$ & 0.641 \\
\hline $\begin{array}{l}\text { ECOG } \\
\text { ECOG } 0+1 \\
\text { ECOG } 2\end{array}$ & $\begin{array}{c}17 \\
1\end{array}$ & $\begin{array}{c}37 \\
3\end{array}$ & 1.0 \\
\hline
\end{tabular}

Table 2: Analysis of the association between the clinicopathological characteristics and the CHK2 immunohistochemical expression status (positive or negative) in colon neoplasm. Caption: stage T (TNM)-T2: tumor invades muscularis propria T3: tumor invades through the muscularis propria and enters pericolorectal tissues, T4: tumor penetrates the visceral peritoneum surface or directly invades it or adheres to other organs or structures; stage N (TNM), N0: No regional lymph node metastasis, N1: Metastasis in 1 to 3 regional lymph nodes, N2: Metastasis in 4 or more regional lymph nodes; ECOG: Eastern Cooperative Oncology Group, degree of cell differentiation: Grade I: well differentiated, grade II: moderately differentiated, and grade III: little differentiated.

compared with CHK2-positive: 89 (95\%CI: 73.7-104.2 months) and 78 months (95\%CI: 53-103 months), respectively $(p=0.05)$.

Independent prognostic factors for OS were synchronous metastasis; advanced ECOG; lower degree of tumor cell differentiation and CHK2positive immunohistochemical expression. For PFS, the prognostic factors were ECOG and the degree of tumor cell differentiation (Tables 3 and 4$)$. 


\begin{tabular}{|l|c|c|c|}
\hline Variable & OR & $\mathbf{9 5 \%} \mathbf{~ C l}$ & p-value \\
\hline CHK2 expression & 11.76 & $1.46-94.23$ & 0.020 \\
\hline Performance status & 77.51 & $7.83-767$ & 0.001 \\
\hline Synchronous metastasis & 5.34 & $1.10-25.88$ & 0.037 \\
\hline Tumor cell differentiation & 9.02 & $1.25-64.66$ & 0.029 \\
\hline Lymph node involvement & 0.24 & $0.05-1.01$ & 0.053 \\
\hline Gender & 0.347 & $0, .093-1.292$ & 0.115 \\
\hline Elderly (>65 years) & 0.437 & $0.126-1.518$ & 0.193 \\
\hline Histology & 1.036 & $0.214-5.016$ & 0.965 \\
\hline OPAA & 3.813 & $0.924-15.742$ & 0.064 \\
\hline Liver metastasis & 0.333 & $0.061-1.807$ & 0.203 \\
\hline Lung metastasis & 0.832 & $0.280-2.476$ & 0.741 \\
\hline
\end{tabular}

Table 3: Independent prognostic factors analyzed by logistic regression analysis for overall survival.

\begin{tabular}{|l|c|c|c|}
\hline Variable & OR & $\mathbf{9 5 \%} \mathbf{C l}$ & p-value \\
\hline CHK2 expression & 1.34 & $0.608-2.973$ & 0.465 \\
\hline Gender & 1.8 & $0.805-4.055$ & 0.152 \\
\hline Elderly (>65 years) & 1.103 & $0.501-2.428$ & 0.808 \\
\hline Histology & 0.57 & $0.213-1.532$ & 0.266 \\
\hline OPAA & 0.857 & $0.409-1.794$ & 0.682 \\
\hline Performance status & 5.62 & $1.463-21.59$ & 0.012 \\
\hline Tumor cell differentiation & 8.79 & $2.434-31.74$ & 0.001 \\
\hline Lymph node involvement & 0.95 & $0.421-2.148$ & 0.903 \\
\hline
\end{tabular}

Table 4: Independent prognostic factors analyzed by logistic regression analysis for progression-free survival.

\section{Discussion}

In the cohort, all the patients presented with metastasis at the time of inclusion in the study. At diagnosis, only 22 (37.8\%) patients had CS II or CS III. The aim of this work was to analyze the CHK2 immunohistochemical expression within the metastatic disease scenario. Immunohistochemical expression was analyzed on the primary colon tumor and not on the metastatic tumor.

The Chk2 molecule constitutes a cell cycle checkpoint kinase that acts as a tumor suppressor-during the cell signaling pathway, it plays an important role in terms of repair and regulation in response to cell DNA damage by diverse agents $[1,2,4,5]$.

The role that CHK2 gene plays during tumorigenesis is little known. However, more advanced tumors, development and progressions tumors have been associated with lower immunohistochemical expression of this protein kinase. Nonetheless, CHK2 (positive or negative expressions) has not been associated with lymph node involvement, patient age, degree of tumor cell differentiation or survival so far $[1,6,10-13]$

The detection of CHK1 and CHK2 germinal mutations in a subgroup of families of the Li Fraumeni syndrome has suggested that these genes act as tumor suppressor genes in sporadic tumors. A study of a subpopulation of patients with the Li Fraumeni syndrome bearing wild $p 53$ but mutated CHK2 confirmed this hypothesis: the investigation found that $\mathrm{CHK} 2$ germinal mutations participate in TP53 inactivation $[4,5]$

Interestingly, loss of $\mathrm{CHK} 2$ expression at the mRNA and protein levels does not occur in the case of vulva carcinomas, whilst $\mathrm{CHK} 2$ expression increases in gastric carcinomas bearing mutation in $p 53$ $[14,15]$.

The pattern of $C H K 2$ immunohistochemical expression in pre- malignant lesions, invasive surface lesions and more advanced lesions of bladder tumors are different. A positive heterogeneous marking exists in early surface lesions and early invasive lesions, whereas reduced marking pattern emerges in more advanced lesions tumors $[5,16]$.

This study found that CHK2 negative immunohistochemical expression was associated with lymph node involvement, which could suggest that the lack of CHK2 expression facilitated the metastatic process to a distant organ. Some authors have already described that low levels of the phosphorylated form of $\mathrm{CHK} 2$ in the cytoplasm are associated with dissemination and invasion of various neoplasms $[3,17]$.

Multivariate regression analysis revealed significantly diminished overall survival in CHK2-positive patients and who presented with synchronous metastasis, worsened clinical conditions and lower degree of cell differentiation. No literature study has investigated how CHK2 immunohistochemical expression is associated with overall survival in patients with metastatic colon cancer, but authors have described increased phosphorylated Chk2 expression is related to higher degree of colon neoplasm malignancy. Indeed, the degree of malignancy implies that the disease behaves more aggressively to negatively affect patient survival [1]. Therefore, positive immunohistochemical protein expression should have a negative prognostic value in patient survival.

Due to its implication in DNA, the CHK2 pathway might represent a potential strategy to targeted cancer therapies. The combination of Chk2 inhibitors and chemotherapeutic agents can be very attractive. Various small molecules can inhibit Chk1 and Chk2 are undergoing pre-clinical trials (CHIR124) and phase I studies (XL844, PF-00477736, AZD7762) [18]. Hence, characterizing patients on the basis of expression molecules that participate in carcinogenesis and that have significant prognostic value will enable researchers to develop tailored and more efficient antineoplastic therapies.

Therefore this is a clinical study of CHK2 immunohistochemical expression in colon cancer and its relation with clinicopathological features and outcome in metastatic colon cancer patients that revealed the negative $C H K 2$ expression association with lymph node involvement and the positive $C H K 2$ expression association with survival. Dual effects of CHK2 expression in colon cancer indicates not only predict clinical aggressiveness but lymph node dissemination candidates. Hitherto, there is no published article about CHK2 expressivity association with survival in patients with metastatic colon cancer, so this study might a preliminary one in opening a new horizon in management of metastatic colon cancer. Therefore as CHK2 expressivity might be an easy tool to be applied on routine pathology reporting, it might represent an impending policy to targeted cancer therapies. Therefore use of anti-neoplastic drugs consisted of Chk2 inhibitors as well as other chemotherapeutic agent spectra could be used unhesitatingly.

\section{Acknowledgements}

We are grateful to Deisy Mara Silva for construction of tissue microarray and performing imunohistochemical reactions.

Contributors K B Ribeiro and J S Zanetti designed the research, coordinated data collection, analysed the data, interpreted the results, and wrote the manuscript. A R Silva, S B Garcia and F M Peria supervised interpretation of study results. O Feres and J J R Ribeiro provided the samples for analysis. All authors reviewed and edited the manuscript and approved the final version of the manuscript.

\section{References}

1. Ribeiro-Silva A, Koyota MMA, Becker MH, Ribeiro do Vale $F$ et al. (2006) Expression of checkpoint kinase 2 in breast carcinomas: correlation with key regulators of tumor cell proliferation, angiogenesis and survival. Histol Histopathol 21:373-382. 
Citation: Ribeiro KB, da Silva Zanetti J, Ribeiro Silva A, Pansani F, Garcia SB, et al. (2014) CHK2 Immunohistochemical Expression in Colon Cancer and its Relation with Clinicopathological Features and Outcome in Metastatic Colon Cancer Patients. J Cytol Histol 5: 288. doi:10.4172/21577099.1000288

Page 5 of 5

2. Bartek J, Lukas J (2003) Chk1 and Chk2 kinases in checkpoint control and cancer. Cancer Cell 3: 421-429.

3. Stawinska M, Cygankiewicz A, Trzcinski R, Mik M, Dziki A, et al. (2008) Alterations of Chk1 and Chk2 expression in colon cancer. Int J Colorectal Dis 23: $1243-1249$.

4. Ahn J, Urist M, Prives C (2004) The Chk2 protein kinase. DNA Repair (Amst) 3: 1039-1047.

5. Williams LH, Choong D, Johnson SA, Campbell IG (2006) Genetic and epigenetic analysis of CHEK2 in sporadic breast, colon, and ovarian cancers. Clin Cancer Res 12: 6967-6972.

6. Sullivan A, Yuille M, Repellin C, Reddy A, Reelfs O, et al. (2002) Concomitan inactivation of p53 and Chk2 in breast cancer. Oncogene 21: 1316-1324.

7. http://www.cancer.gov/dictionary?cdrid=655245

8. Hidalgo A, Piña P, Guerrero G, Lazos M, Salcedo M (2003) A simple method for the construction of small format tissue arrays. J Clin Pathol 56: 144-146.

9. Kilpivaara O, Bartkova J, Eerola H, Syrjäkoski K, Vahteristo P, et al. (2005) Correlation of CHEK2 protein expression and c.1100delC mutation status with tumor characteristics among unselected breast cancer patients. Int $\mathrm{J}$ Cancer 113: $575-580$.

10. Zhang P, Wang J, Gao W, Yuan BZ, Rogers J, et al. (2004) CHK2 kinase expression is down-regulated due to promoter methylation in non-small cell lung cancer. Mol Cancer 3: 14.
11. Vahteristo P, Bartkova J, Eerola H, Syrjäkoski K, Ojala S, et al. (2002) A CHEK2 genetic variant contributing to a substantial fraction of familial breast cancer Am J Hum Genet 71: 432-438.

12. Sullivan A, Yuille M, Repellin C, Reddy A, Reelfs O, et al. (2002) Concomitant inactivation of p53 and Chk2 in breast cancer. Oncogene 21: 1316-1324.

13. Bartkova J, Falck J, Rajpert-De Meyts E, Skakkebaek NE, Lukas J, et al. (2001) Chk2 tumour suppressor protein in human spermatogenesis and testicular germ-cell tumours. Oncogene 20: 5897-5902.

14. Reddy A, Yuille M, Sullivan A, Repellin C, Bell A, et al. (2002) Analysis of CHK2 in vulval neoplasia. Br J Cancer 86: 756-760.

15. Shigeishi H, Yokozaki H, Oue N, Kuniyasu H, Kondo T, et al. (2002) Increased expression of $\mathrm{CHK} 2$ in human gastric carcinomas harboring p53 mutations. In J Cancer 99: 58-62.

16. Bartkova J, Horejsí Z, Koed K, Krämer A, Tort F, et al. (2005) DNA damage response as a candidate anti-cancer barrier in early human tumorigenesis. Nature 434: 864-870.

17. Matsuoka S, Nakagawa T, Masuda A, Haruki N, Elledge SJ, et al. (2001) Reduced expression and impaired kinase activity of a Chk2 mutant identified in human lung cancer. Cancer Res 61: 5362-5365.

18. Pires IM, Ward TH, Dive C (2010) Oxaliplatin responses in colorectal cancer cells are modulated by CHK2 kinase inhibitors. Br J Pharmacol 159: 1326 1338 . 